\title{
A didática da resolução de problemas nas séries iniciais: um problema para o aluno ou para o professor?
}

\author{
The teaching problem solving in the early grades: a problem for the student or the teacher? \\ V. G. S. Campos; D. N. Souza; V. A. Silva \\ Programa de Pós Graduação em Ensino de Ciências e Matemática, Universidade Federal de Sergipe, 49100-00, São \\ Cristóvão-Sergipe, Brasil \\ vanessayadah@hotmail.com
}

(Recebido em 24 de fevereiro de 2016; aceito em 05 de junho de 2016)

\begin{abstract}
Este artigo é fruto de uma análise de concepções sobre resolução de problemas matemáticos, considerandose as opiniões de quatro professoras que lecionam o terceiro ano do ensino fundamental em Aracaju, SE, que atuam na rede pública e privada de ensino. Através de entrevistas, as professoras expuseram a forma como trabalham com a resolução de problemas e suas principais dificuldades. Os relatos das professoras evidenciaram que elas consideram importante o trabalho com a resolução de problemas no ensino da Matemática, embora elas não possuam embasamento teórico as que oriente nessa prática e, por isso, agem em sala de aula de acordo com o que vão aprendendo no dia a dia. Desta forma, foi possível perceber que a resolução de problemas não é vista como tarefa fácil, nem para o aluno, nem para o professor.
\end{abstract}

Palavras-chave: Resolução de Problemas; Dificuldades de Ensino.

This article is the result of an analysis of conceptions on mathematical problems solving, considering the opinions of four teachers who teach the third grade of elementary school in Aracaju, SE, working in public and private schools. Through interviews, the teachers showed how working with the resolution of problems and their main difficulties. The accounts of teachers showed they believe that it's important to work with the resolution of problems in the teaching of mathematics, although they do not have theoretical basis to guide this practice and, therefore, act in the classroom according to what they're going to learning on a daily basis. Thus, it was possible to notice that the resolution of problems is not seen as easy task nor for the student or teacher.

Keywords: Teaching; Troubleshooting; Learning difficulties.

\section{INTRODUÇÃO}

Há muito o que se colocar numa discussão acerca da resolução de problemas no ensino da Matemática nas séries iniciais do ensino fundamental e o fato da disciplina ser ministrada por professores polivalentes, que em sua formação docente veem bem pouco, ou nada, dos conteúdos matemáticos. As formas de ensino e aprendizagem da Matemática para essas séries fomentam sérios questionamentos sobre a maneira como as aulas se processam no cotidiano escolar e sobre as visões e perspectivas que os professores têm acerca dos conteúdos que eles ensinam nessa disciplina.

Embora o discurso preponderante no cenário educacional seja o de que o ensino deva trabalhar a criticidade e a busca pela descoberta e o raciocínio dedutivo dos alunos, o trabalho que vemos em muitas escolas ainda está centrado em procedimentos mecânicos e desprovidos de significação.

Um dos objetivos do ensino fundamental, expressos nos Parâmetros Curriculares Nacionais (PCN's) para o ensino de matemática é

Questionar a realidade formulando-se problemas e tratando de resolvêlos, utilizando para isso o pensamento lógico, a criatividade, a intuição, a capacidade de análise crítica, selecionando procedimentos e verificando sua adequação [1].

Em relação à resolução de problemas matemáticos, há divergências na compreensão que os educadores têm sobre o que vem a ser um problema. Muitos professores trabalham com problemas 
matemáticos, mas não param para refletir sobre a influência que estes trazem para a aprendizagem e Matemática, por isso, não aproveitam o potencial deles.

Nas Diretrizes Curriculares da Educação Básica de Matemática, a resolução de problemas é apresentada como "uma metodologia pela qual o estudante tem oportunidade de aplicar conhecimentos matemáticos adquiridos em novas situações, de modo a resolver a questão proposta" [2]. Ou seja, o professor dá início à apresentação de um conteúdo, provocando os estudantes por meio de problemas.

Dante [3] enfatiza que há diversos tipos de problemas e classifica-os em seis, conforme sua abordagem e finalidade:

1- Os Problemas-Padrão, cuja solução já está contida no próprio enunciado, devendo o aluno identificar os dados e traduzi-los na linguagem matemática para aplicar as operações necessárias à sua resolução. Tem como objetivo a fixação de fatos básicos recém ensinados por meio de algoritmos das quatro operações fundamentais e a vinculação destas operações em situações do cotidiano.

2- Os problemas-Processo ou Heurísticos, que não podem ser resolvidos pela aplicação automática de algoritmos, pois as operações não estão explícitas nos enunciados e os alunos precisam arquitetar estratégias que poderão levá-los à solução.

3- Problemas de Aplicação, também chamados de situações-problemas ou contextualizados, valem-se de conceitos, técnicas e procedimentos para matematizar situações reais. Costumam aplicar gráficos, tabelas e operações e podem ser apresentados em formas de projetos envolvendo aspectos de outras disciplinas.

4- Problemas de Quebra-Cabeça, cuja solução depende da percepção de regularidades. Como charadas ou desafios, estes problemas envolvem os alunos na chamada matemática recreativa.

5- Exercícios de Reconhecimento, para que os alunos reconheçam, lembrem ou identifiquem determinado conceito, ou definição, ou propriedade...

6- Exercícios de Algoritmos, que podem ser resolvidos passo a passo, com o objetivo de reforçar conhecimentos anteriores e treinar habilidades na resolução de algoritmos

Clement e Térrazant [4] afirmam que "apesar de vários professores mencionarem que realizam, normalmente, práticas de resolução de problemas em sala de aula, o que realmente fazem é a resolução de "exercícios". Para esses autores, um exercício pode ser resolvido usando um algoritmo ou método já conhecido pelos alunos enquanto que para o problema o aluno não dispõe de um método imediato de resolução.

Independentemente do tipo de problema, Polya [5] sugeriu um esquema de etapas a serem seguidas nas resoluções de problemas. Este esquema inclui a compreensão do problema, destacando informações oferecidas, a elaboração de um plano para resolvê-lo, a execução deste plano, a verificação ou retrospecto deste plano e elaboração de novas estratégias, se necessário, até se chegar à solução. Estas não são etapas rígidas, nem infalíveis, mas têm a intenção de orientar o solucionar da questão.

\section{MATERIAL E MÉTODOS}

Este artigo aborda os resultados parciais de uma pesquisa em andamento junto a professores com formação em pedagogia, que atuam em escolas públicas e privadas na cidade de Aracaju. Delimitou-se como principal objetivo a investigação sobre como se dá a resolução de problemas nas turmas do terceiro ano do ensino fundamental.

O trabalho de campo deste estudo é constituído de entrevistas por pautas realizadas com quatro professoras que lecionam o terceiro ano do ensino fundamental na cidade de Aracaju, das quais duas trabalham em escolas da rede municipal e duas em escolas da rede de ensino particular.

Conforme Gil,

A entrevista por pauta apresenta certo grau de estruturação, já que se guia por uma relação de pontos de interesse que o entrevistador vai explorando ao longo do seu curso. [...] O entrevistador faz poucas perguntas diretas 
e deixa o entrevistado falar livremente à medida que refere às pautas assinaladas. Quando este se afasta delas, o entrevistador intervém, embora de maneira suficientemente sutil, para preservar a espontaneidade do processo [6].

Questionou-se às entrevistadas sobre sua prática docente diária. Para reproduzir com precisão os comentários das professoras, fez-se o registro das respostas, com anotações no ato de cada entrevista. $\mathrm{O}$ recurso do gravador foi dispensado de modo a garantir que as entrevistadas não se sentissem inibidas. Após a transcrição dos relatos, foi feita a análise das falas buscando relacionar as respostas dadas pelas entrevistadas a um embasamento teórico para conduzir as argumentações ratificando ou retificando as informações obtidas. Para facilitar a distinção entre as entrevistadas e garantir a preservação da identidade de cada uma delas, optou-se por classificá-las em: P.MUN.1 e P.MUN.2 (para as professoras da rede municipal) e P.PART.1 e P.PART.2 (para as professoras da iniciativa privada).

\section{RESULTADOS E DISCUSSÃO}

As entrevistas foram realizadas nas próprias escolas onde as professoras trabalham. A duração de cada entrevista foi, em média, de 15 a 30 minutos. Todas as entrevistadas mostraram-se atenciosas, solícitas e satisfeitas em contribuir com a pesquisa. Apenas uma professora, identificada como P.PART2 é recém-formada, as outras graduaram-se há mais de dez anos e atuam na área desde então.

$\mathrm{O}$ primeiro questionamento feito às entrevistadas foi você trabalha com problemas matemáticos? Se sim, como?

A resposta de todas foi sim, mas houve algumas diferenciações no como, devido ao fato de trabalharem em realidades e com clientelas diferentes (escolas públicas e privadas). Todas as professoras utilizam predominantemente os problemas contidos nos livros que são adotados pelas escolas nas quais trabalham, mas duas (as da rede municipal) alegaram buscar também problemas na internet, além de criarem episódios de conversação com os alunos, apoiando-se em situações hipotéticas, ou que de fato ocorram com eles em sala de aula, para provocar a reflexão dos alunos. Uma das professoras narrou, a título de exemplo, uma situação vivenciada recentemente:

(P.MUN.1) Para fazer um trabalho outro dia, eu disse que queria seis grupos. Daí os alunos contaram quantos alunos estavam na sala naquele dia (tinha 24) e fizeram a divisão exata.

Essa postura de apresentar situações reais e deixar os alunos buscarem, de maneira autônoma, alternativas para solucionar a questão que lhes fora apresentada está de acordo com as ideias de Smole e Diniz [7], quando estas colocam que o professor deve garantir um espaço de discussão no qual os estudantes reflitam sobre os problemas a serem resolvidos, elaborem estratégias e apresentem hipóteses. Isso enriquece a produção do pensamento matemático livre do apego às regras. Os estudantes podem valer-se de recursos como o desenho, a oralidade e outros, até sentirem-se preparados para empregar os sinais matemáticos.

Ao perguntar se, na opinião delas, o problema matemático trata-se de conteúdo ou de estratégia didática? Apenas uma respondeu ser conteúdo. As demais responderam ser o problema uma forma de se trabalhar outros conteúdos, principalmente as quatro operações.

Smole, Diniz e Cândido [8] afirmam que "Não se trata também de considerar a resolução de problemas como um conteúdo isolado dentro do currículo". Sabemos que a resolução de problemas configura um caminho metodológico para conduzir ensinamentos matemáticos, assim como a etnomatemática, a modelagem, a história da matemática, dentre outros.

$\mathrm{O}$ terceiro questionamento foi quais (e para a professora que respondeu ser conteúdo, que outros) conteúdos são trabalhados através da resolução de problemas? Apesar de terem sido entrevistadas separadamente, as professoras tiveram atitudes bastante semelhantes ao responderem este quesito. Todas responderam, de imediato, as quatro operações e o sistema monetário. Passados uns instantes, começaram a colocar, também, medidas de tempo, massa, volume e comprimento. 
Uma das entrevistadas afirmou utilizar os problemas de forma interdisciplinar, focando a interpretação de texto. Outra professora respondeu utilizar os conteúdos de ciências para embasar problemas e, deste modo, mesmo trabalhando matemática, reforçar os conteúdos da outra disciplina.

A quarta e última questão foi qual a maior dificuldade de trabalhar com resolução de problemas? Este foi o questionamento que trouxe maior divergência nas repostas:

(P.MUN.1) A maior dificuldade é o aluno entender a abstração do enunciado. O problema da divisão entre os alunos da turma, como falei, eles resolveram rapidinho e certo, mas porque foi com eles ali. Se fosse uma situação bem parecida, só que no papel, eles teriam mais dificuldade.

Em relação à abstração, os PCN's colocam que

A abstração matemática revela-se no tratamento de relações quantitativas e de formas espaciais, destacando-as das demais propriedades dos objetos. A Matemática move-se quase exclusivamente no campo dos conceitos abstratos e de suas inter-relações. Para demonstrar suas afirmações, o matemático emprega apenas raciocínios e cálculos [1].

Sem desconsiderar que a abstração é um traço característico da Matemática que deve ser trabalhado desde os anos iniciais, esse depoimento apresentado pela professora está de acordo com a teoria de Piaget [9], pois os alunos encontram-se na faixa etária do estágio das operações concretas, no qual as crianças dependem do mundo concreto para abstrair e as atitudes são realizadas a fim de organizar a sua realidade pela capacidade de resolver problemas concretos. Por isso, essa dificuldade em relação à abstração pode ser compreendida como natural [10]. Para trabalhar nessa fase, Dante [3] sugere a criação de oportunidades para as crianças usarem materiais manipulativos (tampinhas, cartazes, tabelas, palitos, ...) na resolução de problemas. A manipulação e as atividades mentais relacionadas a ela permitirão, gradativamente, a abstração das ideias.

A outra professora da rede municipal citou a interpretação textual como maior dificuldade:

(P.MUN.2) O difícil é eles (os alunos) entenderem o que o problema está sendo pedido. A dificuldade está na interpretação de texto. E olha que eu coloco a situação, tento fazer com que eles analisem e reflitam o que a situação está exigindo para que eles compreendam que operação eles devem aplicar. Por isso, busco fazer um trabalho interdisciplinar com interpretação de texto. Além disso, outra coisa que dificulta é a quantidade de alunos e o mobiliário grande. Resultado: os alunos ficam todos muito próximos e ficam se dispersando.

Quanto a isso, Costa e Fonseca [11] afirmam que o sucesso na resolução dos problemas depende "não só do nível de competências manifestadas em matemática, dos conceitos envolvidos na resolução de tarefas, mas essencialmente das competências manifestadas na Língua Portuguesa". Essa citação corrobora com a teoria de Vigotsky [12], que traz a ideia de que a linguagem tanto evidencia o pensamento como opera na organização do mesmo.

A professora da rede particular de ensino colocou como dificuldade maior a efetuação dos cálculos:

(P.PART.1) O maior problema é a tabuada. Eles entendem o enunciado. A maior dificuldade é a resolução do cálculo. Eles já leem e compreendem. Por isso a dificuldade é o cálculo mesmo. Quando fiz meu estágio num colégio da prefeitura, o problema era o enunciado porque eles mal sabiam ler, mas nessa escola eles já chegam no terceiro ano lendo tudo direitinho.

Esse depoimento está de acordo com Vergnaud [13] quando este traz a ideia de que os cálculos numéricos ocorrem pela manipulação e resolução de um algoritmo, independentemente dos aspectos semânticos e estruturais de uma situação-problema. Assim, mesmo quando os alunos conseguem compreender o sentido situacional trazido num determinado problema, ainda podem encontrar dificuldades em resolvê-lo no momento de efetuar os cálculos. 
A última professora entrevistada, assim como a professora da rede municipal, colocou que a grande dificuldade de se trabalhar com problemas em sala de aula é a interpretação de texto para que os alunos percebam a lógica situacional exposta:

(P.PART.2) Levar o aluno ao raciocínio lógico. O maior problema é a interpretação. Eles têm facilidade de calcular.

Novamente a dificuldade recai sobre a questão da interpretação, que está diretamente relacionado ao uso da linguagem. Nesta situação, a linguagem usual, por não ser bem compreendida, é que dificulta a resolução do problema pois, se não houver clareza, não há possibilidade de os alunos perceberem a lógica situacional envolvida no problema. Ou seja, as dificuldades podem não estar situadas no âmbito dos algoritmos, das fórmulas ou dos conceitos específicos dessas áreas, mas sim nas construções linguístico-discursivas dos enunciados dos problemas, conforme consta em Azevedo e Rowell [14]. Ainda para esses autores, são dificuldades de nível lexical, sintático, semântico, textual e/ou discursivo que impedem os alunos de resolver adequadamente os problemas por não poderem recuperar sua unidade de sentido.

\section{CONCLUSÃO}

O emprego de situações-problema no terceiro ano do ensino fundamental favorece a construção significativa das operações fundamentais e a compreensão de que uma mesma operação pode estar relacionada a situações diferenciadas, ou que uma mesma situação pode requerer mais de uma operação [3].

No entanto, mesmo sabendo da importância de se trabalhar com a resolução de problemas, muitos professores sentem dificuldade de envolvê-la em sua didática, e por isso evitam, ou limitamna ao uso de problemas-padrão. A falta de estratégias que incentivem os alunos, a dificuldade de transpor a linguagem usual para a linguagem matemática e o pouco entendimento dos alunos em relação a que tipo de cálculo determinada situação está pedindo são alguns dos fatores que aumentam a desmotivação do professor em buscar a problematização nas salas de aulas.

Percebeu-se que as professoras entrevistadas, por exemplo, trabalham a resolução de problemas pela necessidade ou obrigatoriedade de cumprir o programa de ensino, e que há pouca variedade dos tipos de problemas ofertados aos alunos, pois embora haja a preocupação em trazer abordagens diferenciadas (buscando envolver elementos do entorno dos alunos e de outras disciplinas) os problemas propostos por elas em sala de aula são para fixação dos algoritmos ensinados.

O trabalho com o ensino de Matemática traz grandes desafios, especialmente aos professores que lecionam as séries iniciais e não tiveram, em sua formação, fundamentos matemáticos. As dificuldades apresentadas na pesquisa são características inerentes à resolução de problemas e ao ensino da matemática. Logo, tais dificuldades estarão sempre presentes nas salas de aula, não devendo, portanto, servirem de obstáculos à motivação do professor na realização de seu trabalho pedagógico. Todo trabalho exige empenho e dedicação. Ademais, o professor é um modelo para seus alunos e, por isso, não deve esmorecer diante das dificuldades encontradas ao executar suas tarefas. Do contrário, não será capaz de despertar nos outros o sentimento de entusiasmo pelo conteúdo que está a ensinar [15].

\section{REFERÊNCIAS BIBLIOGRÁFICAS}

1. Brasil. Ministério da Educação. Secretaria de Educação Fundamental. Parâmetros curriculares nacionais. Matemática: $3^{\circ}$ e $4^{\circ}$ ciclo do Ensino Fundamental. Brasília: MEC/SEF, 1998

2. Paraná, Secretaria de Estado da Educação. Diretrizes Curriculares da Educação Básica. Curitiba: SEED/DEB-PR, 2008.

3. Dante LR. Formulação e resolução de problemas de matemática: teoria e prática. São Paulo: Ática, 2010.

4. Clement L, Terrazzan EA. atividades didáticas de resolução de problemas e o ensino de conteúdos procedimentais. Revista Electrónica de Investigación en Educación en Ciencias, v. 6, n. 1, jul. 2011. 
5. Polya G. A arte de resolver problemas. Primeira reimpressão. Tradução e adaptação de Heitor Lisboa de Araújo. Rio de janeiro: Interciências, 1986.

6. Gil AC. Métodos e técnicas de pesquisa social. 6.ed. São Paulo: Editora Atlas, 2008.

7. Smole KCS, Diniz MI (orgs.). Ler, Escrever e Resolver Problemas: habilidades básicas para aprender matemática. Porto Alegre, Artmed, 2001.

8. Smole KCS, Diniz MI, Cândido P. Resolução de problemas: Matemática de 0 a 6. Porto Alegre: Artmed, 2000.

9. Piletti N, Rossato SM. Psicologia da aprendizagem: da teoria do condicionamento ao construtivismo. São Paulo: Contexto, 2011.

10. Piaget J. Problemas de psicologia genética. Rio de Janeiro: Forense, 1973.

11. Costa AM, Fonseca L. Os números na interface da língua portuguesa e da matemática - Actas do XIXEIEM. Vila Real: Sociedade Portuguesa de Investigação em Educação Matemática. 2009

12. Vigotsky, LS. Teoria e método em psicologia. São Paulo, Martins Fontes, 1996.

13. Vergnaud G. El ninõ, las matemáticas y la realidade: problemas de la ensenanza de las matemáticas em la escuela primaria. Editorial Trillas, México, 1991.

14. Azevedo TM, Rowell VM. Problematização e ensino de língua materna. In: Seminário Nacional sobre Linguagem e Ensino, 5, Pelotas. 2007

15. Bruner JS. O processo da educação. 3 ed. São Paulo: Nacional, 1972. 